\title{
Pengaruh Promosi dan Harga Terhadap Keputusan Pada Pembelian PT. Shopee International Indonesia Di Kota Manado
}

\author{
Sharen G. Tulanggow \\ Tinneke M. Tumbel \\ Olivia Walangitan \\ Jurusan Ilmu Administrasi, Program Studi Administrasi Bisnis \\ Fakultas Ilmu Sosial dan Politik Universitas Sam Ratulangi \\ E-mail: sharengtulangow@gmail.com
}

\begin{abstract}
This study aims to determine the effect of promotion and price on purchasing decisions at PT. Shopee International Indonesia in the city of Manado, where Shopee consumers in the city of Manado also often shop through this application by looking at the promotions that PT. Shopee International Indonesia often holds and the prices offered so that in purchasing decisions there are several factors that influence in it, and this research the writer takes the promotion and price factors. In this research quantitative associative research is used with data collection techniques by observation and questionnaire. The analysis technique used is the validity test, reliability test, normality test, multiple linear regression analysis, coefficient of determination analysis. In testing the hypothesis using partial test and simultaneous test. Based on the results obtained from this study, it shows that the influence of promotion is $52.9 \%$ and the influence of price is $40.3 \%$. and the effect of promotion and price simultaneously that is equal to $56.6 \%$ while the remaining $43.4 \%$ is explained by other variables not included in this study that include products, places, people, processes, advertising, physical evidence.
\end{abstract}

Keywords: Promotion, Price, Purchase Decision

\section{Pendahuluan}

Promosi yaitu bahwa promosi mengacu pada kegiatan berkomunikasi dengan manfaat dari produk dan membujuk pelanggan untuk membeli produk tersebut (Kotler dan Armstrong 2014).

Harga merupakan bagian penentu yang ada dalam suatu penjualan, dan setiap produk yang dijual pasti memiliki harga yang dicantumkan. Harga merupakan sejumlah uang yang dikeluarkan oleh konsumen untuk sebuah produk dan jasa atau sejumlah nilai yang ditukarkan oleh konsumen untuk memperoleh manfaat atau kepemilikan atau penggunaan atas sebuah produk atau jasa (Kotler dan Amstrong 2016). Keputusan pembelian merupakan bagian dari perilaku konsumen perilaku konsumen yaitu studi tentang bagaimana individu, kelompok, dan organisasi memilih, membeli, menggunakan, dan bagaimana barang, jasa, ide atau pengalaman untuk memuaskan kebutuhan dan keinginan mereka (Kotler \& Armstrong 2016) 
Indikator-indikator dalam promosi yaitu: iklan, penjualan pribadi, promosi penjualan, publisitas (Kotler 2009), indicator-indikator dalam harga yaitu: keterjangkauan harga, harga sesuai kemampuan atau daya saing harga, kesesuaian harga dengan kualitas produk, kesesuaian harga dengan manfaat (Kotler dan Amstrong 2012), sedangkan indikatorindikator dalam keputusan pembelian yaitu: pilihan produk, pilihan merek, pilihan penyalur, waktu pembelian, jumlah pembelian, metode pembayaran (Kotler \& Armstrong 2016). Proses keputusan pembelian terdiri dari lima tahap, yaitu pengenalan masalah, pencarian informasi, evaluasi alternatif, keputusan pembelian dan perilaku pasca pembelian (Kotler dan Keller 2009)

Dalam mempromosikan merek perusahaan, PT. Shopee Internasional Indonesia memiliki slogan berupa "Gratis Ongkos Kirim Se-Indonesia” yang merupakan program promosi andalan yang memiliki daya tarik tersendiri bagi penggunanya karena dalam membeli sebuah barang melalui online, konsumen harus menambah biaya sebagai ongkos dalam pengiriman barang. Sehingga banyak pengguna Shopee yang mencoba berbelanja di Shopee karena dianggap cukup menguntungkan bagi pelanggan yang gemar berbelanja online. Namun, promosi gratis ongkos kirim se-Indonesia tidak berlaku di semua toko yang bergabung di Shopee, hanya toko yang bertanda khusus yang berlaku gratis ongkos kirim ini, tapi dalam promosi ini memiliki kesenjangan yang ada yaitu hanyalah sebatas potongan ongkos kirim dan bukan gratis ongkos kirim seperti yang selalu dipromosikan. Dan saat pembelian untuk mendapatkan potongan ongkos kirim inipun harus ada minimal jumlah pesanan yang ditetapkan. ada yang sampai ongkos pengiriman barang lebih mahal dibanding dengan harga barang yang akan dibeli.

Di dalam PT. Shopee Internasional Indonesia, terdapat banyak toko yang bergabung di dalamnya, sehingga menimbulkan beragam harga yang ditawarkan. Perbedaan utama antara belanja online dan pembelian secara langsung ditoko adalah kemampuan pelanggan untuk menilai suatu produk sehingga dapat menimbulkan keinginan hingga keputusan pembelian. Pada belanja online calon pembeli tidak dapat memeriksa barang yang mereka ingin beli secara langsung dan biasanya hanya dibantu oleh gambar ataupun deskripsi yang diberikan oleh penjual, sedangkan pada toko ritel kita dapat melihat maupun menyentuh barang secara fisik. Selain itu pada belanja online, proses pembayaran juga menjadi kendala karena kebanyakan 
belanja online mengharuskan kita mentransfer sejumlah dana terlebih dahulu sebelum barang dapat diantar ke rumah. Untuk itu tentu perlu adanya kepercayaan yang tinggi jika berbelanja online agar kita berani untuk melakukan pembayaran dengan cara seperti tersebut. Cara pembayaran lain biasanya adalah dengan menggunakan kartu kredit, sedangkan pada pembelian secara langsung ditoko kita bisa langsung membayar dengan uang tunai.

Produk yang ditawarkan setiap toko seringkali memiliki tingkat kualitas yang sama tetapi harga yang berbeda. Perbedaan yang terjadi contohnya toko A menawarkan harga yang rendah sedangkan toko B menawarkan harga yang tinggi dengan kualitas produk yang sama yaitu standar, sehingga membuat konsumen merasa dirugikan karena saat pembelian, harga yang ditawarkan berbeda tapi produk yang dibeli sama yaitu dengan kualitas standar.

\section{Penelitian Terdahulu}

Wariki, Grace. 2015. Pengaruh Bauran Promosi, Persepsi Harga Dan Lokasi Terhadap Keputusan Pembelian Dan Kepuasan Konsumen Pada Perumahan Tamansari Metropolitan Manado. Penelitian ini bertujuan untuk menganalisis pengaruh bauran promosi, persepsi harga dan lokasi terhadap keputusan pembelian dan kepuasan konsumen pada Perumahan
Tamansari Metropolitan Manado. Metode Analisis yang digunakan adalah analisis jalur. Populasi penelitian berjumlah 218, sampel berjumlah 135 responden. Hasil penelitian menunjukkan bauran promosi berpengaruh positif dan signifikan terhadap keputusan pembelian dan kepuasan konsumen.

Budiyanto, Teguh. 2016. Strategi Promosi, Kualitas Produk, Dan Desain Terhadap Keputusan Pembelian Dan Minat Mereferensikan Rumah Pada Puri Camar Liwas PT. Camar Sapta Ganda. Penelitian ini bertujuan untuk mengetahui seberapa besar pengaruh harga, kualitas produk dan promosi pada keputusan konsumen untuk membeli sepeda motor merek Honda di Kota Semarang. Hasil analisis awal yang dilakukan menunjukan bahwa indikator yang digunakan valid untuk mengukur variabel yang ada. Hasil analisis selanjutnya mendapati bahwa dari ketiga variabel yang digunakan dalam penelitian ini, harga menjadi variabel yang paling dominan dalam mempengaruhi keputusan pembelian dengan koefisien regresi sebesar 0,397 diikuti variabel kualitas produk dengan koefisien regresi sebesar 0,318 dan variabel promosi dengan koefisien regresi sebesar 0,260. Hasil analisis juga menunjukkan bahwa ketiga variabel yang digunakan dalam penelitian ini dapat menjelaskan $51,3 \%$ variasi keputusan 
pembelian, sedangkan $48,7 \%$ sisanya dijelaskan oleh faktor lain yang tidak digunakan dalam penelitian ini.

Gerung, Christy. 2017. Pengaruh Kualitas Produk, Harga Dan Promosi Terhadap Keputusan Pembelian Mobil Nissan X-Trail Pada PT. Wahana Wirawan Manado. Tujuan penelitian ini yaitu untuk menganalisis pengaruh kualitas produk, harga dan promosi terhadap keputusan pembelian mobil Nissan X-Trail pada PT. Wahana Wirawan Manado. Hasil Penelitian menunjukkan bahwa Kualitas Produk, Harga dan Promosi secara simultan maupun parsial berpengaruh signifikan terhadap Keputusan Pembelian mobil Nissan X-Trail pada PT. Wahana Wirawan Manado.

\section{Metode Penelitian}

$\begin{array}{rlr}\text { Menurut } & \text { Sugiyono } & \text { (2015) } \\ \text { mendefinisikan } & \text { metode } & \text { penelitian }\end{array}$
kuantitatif sebagai metode penelitian yang berlandaskan pada filsafat positifme, digunakan untuk meneliti pada populasi atau sampel tertentu, pengumpulan data menggunakan instrumen penelitian, analisis data bersifat kuantitatif, dengan tujuan untuk menguji hipotesis yang telah ditetapkan. Sedangkan penelitian ini menggunakan tipe atau jenis penelitian asosiatif, dimana menurut Siregar (2013), tipe penelitian bertujuan untuk mencari hubungan diantara dua variabel. Dan pada penelitian ini, sampel penelitian yang digunakan adalah Genuie Sampling, yang sumber datanya adalah data primer dan data sekunder. Teknik analisis data yang digunakan adalah uji validitas, uji realibilitas, uji normalitas, analisis regresi linear berganda, hipotesis uji, hipotesis uji $\mathrm{F}$, analisis koefisien determinasi.

\section{Hasil Penelitian}

\subsubsection{Uji Validitas}

\subsubsection{Hasil Uji Validitas Promosi}

Validitas Promosi

\begin{tabular}{|c|c|c|c|}
\hline Variabel & $r_{\text {tabel }}$ & $\mathrm{r}_{\text {hitung }}$ & ket \\
\hline X1.1 & \multirow{4}{*}{0,256} & 0,725 & Valid \\
\hline X1.2 & & 0,837 & Valid \\
\hline $\mathrm{X} 1.3$ & & 0,819 & Valid \\
\hline X1.4 & & 0,723 & Valid \\
\hline
\end{tabular}

Dilhat dari hasil diatas dinyatakan bahwa :

$\mathrm{X} 1.1$ dinyatakan valid karena nilai $\mathbf{r}_{\text {hitung }}$ sebesar 0,725 lebih besar dari $r_{\text {tabel }}$ sebesar 0,256 .

$\mathrm{X} 1.2$ dinyatakan valid karena nilai $\mathrm{r}_{\text {hitung }}$ sebesar 0,837 lebih besar dari $r_{\text {tabel }}$ sebesar 0,256 .

$\mathrm{X} 1.3$ dinyatakan valid karena nilai $\mathrm{r}_{\text {hitung }}$ sebesar 0,819 lebih besar dari $r_{\text {tabel }}$ sebesar 0,256 .

$\mathrm{X} 1.1$ dinyatakan valid karena nilai $\mathrm{r}_{\text {hitung }}$ sebesar 0,723 lebih besar dari $r_{\text {tabel }}$ sebesar 0,256 .

\subsubsection{Hasil Uji Validitas Harga}

\begin{tabular}{|l|l|l|l|}
\hline Variabel & $\mathrm{r}_{\text {tabel }}$ & $\mathrm{r}_{\text {hitung }}$ & Ket \\
\hline
\end{tabular}




\begin{tabular}{|l|l|l|l|}
\hline $\mathrm{X} 2.1$ & \multirow{4}{*}{0,256} & 0,659 & Valid \\
\cline { 1 - 1 } $\mathrm{X} 2.2$ & 0,928 & Valid \\
\cline { 1 - 1 } $\mathrm{X} 2.3$ & & 0,924 & Valid \\
\cline { 4 - 4 } $\mathrm{N} 2.4$ & & 0,953 & Valid \\
\hline
\end{tabular}

Dilihat dari hasil diatas dinyatakan bahwa :

X2.1 dinyatakan valid karena nilai $r_{\text {hitung }}$ sebesar 0,659 lebih besar dari $r_{\text {tabel }}$ sebesar 0,256 .

$\mathrm{X} 2.1$ dinyatakan valid karena nilai $\mathrm{r}_{\text {hitung }}$ sebesar 0,928 lebih besar dari $r_{\text {tabel }}$ sebesar 0,256 .

X2.1 dinyatakan valid karena nilai $r_{\text {hitung }}$ sebesar 0,924 lebih besar dari $r_{\text {tabel }}$ sebesar 0,256 .

X2.1 dinyatakan valid karena nilai $r_{\text {hitung }}$ sebesar 0,953 lebih besar dari $r_{\text {tabel }}$ sebesar 0,256 .

\subsubsection{Hasil Uji Validitas Keputusan} Pembelian

\begin{tabular}{|c|c|c|c|}
\hline variabel & $r_{\text {tabel }}$ & $\mathrm{r}_{\text {hitung }}$ & Ket \\
\hline Y1.1 & \multirow{6}{*}{0,256} & 0,839 & Valid \\
\hline Y1.2 & & 0,874 & Valid \\
\hline Y1.3 & & 0,878 & Valid \\
\hline Y1.4 & & 0,909 & Valid \\
\hline Y1.5 & & 0,874 & Valid \\
\hline Y1.6 & & 0,708 & Valid \\
\hline
\end{tabular}

Dilihat dari hasil diatas dinyatakan bahwa :

Y1.1 dinyatakan valid karena nilai $\mathrm{r}_{\text {hitung }}$ sebesar 0,839 lebih besar dari $\mathrm{r}_{\text {tabel }}$ sebesar 0,256.

Y1.2 dinyatakan valid karena nilai $\mathrm{r}_{\text {hitung }}$ sebesar 0,874 lebih besar dari $\mathrm{r}_{\text {tabel }}$ sebesar 0,256.
Y1.3 dinyatakan valid karena nilai $r_{\text {hitung }}$ sebesar 0,878 lebih besar dari $r_{\text {tabel }}$ sebesar 0,256.

Y1.4 dinyatakan valid karena nilai $\mathrm{r}_{\text {hitung }}$ sebesar 0,909 lebih besar dari $\mathrm{r}_{\text {tabel }}$ sebesar 0,256.

Y1.5 dinyatakan valid karena nilai $\mathrm{r}_{\text {hitung }}$ sebesar 0,874 lebih besar dari $\mathrm{r}_{\text {tabel }}$ sebesar 0,256.

Y1.6 dinyatakan valid karena nilai $\mathrm{r}_{\text {hitung }}$ sebesar 0,708 lebih besar dari $\mathrm{r}_{\text {tabel }}$ sebesar 0,256 .

\subsubsection{Hasil Uji Realibilitas}

\begin{tabular}{|c|c|c|c|}
\hline variabel & $\mathrm{r}_{\text {tabel }}$ & $\mathrm{r}_{\text {hitung }}$ & Ket \\
\hline \multirow{3}{*}{$\mathrm{X} 1$} & \multirow{2}{*}{0,06} & 0,752 & Reliabel \\
\cline { 1 - 2 } $\mathrm{n} 2$ & 0,896 & Reliabel \\
\cline { 1 - 2 } & & 0,921 & Reliabel \\
\hline $\mathrm{Y}$ & &
\end{tabular}

Dilihat dari hasil diatas dinyatakan bahwa :

X1 dinyatakan reliabel karena nilai $r_{\text {hitung }}$ sebesar 0,752 lebih besar dari $r_{\text {tabel }}$ sebesar 0,06.

X2 dinyatakan reliabel karena nilai $\mathrm{r}_{\text {hitung }}$ sebesar 0,896 lebih besar dari $\mathrm{r}_{\text {tabel }}$ sebesar 0,06.

Y dinyatakan reliabel karena nilai $r_{\text {hitung }}$ sebesar 0,921 lebih besar dari $r_{\text {tabel }}$ sebesar 0,06 .

\subsubsection{Uji Normalitas}

One-Sample Kolmogorov-Smirnov Test

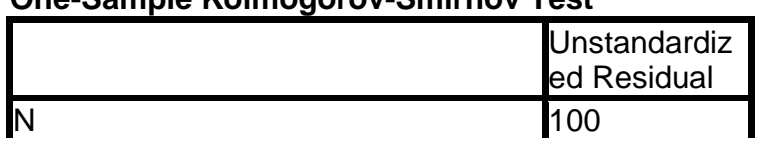




\begin{tabular}{|c|c|c|}
\hline $\begin{array}{l}\text { Normal Parameters } \\
\text { Most Extreme } \\
\text { Differences } \\
\text { Test Statistic } \\
\text { Asymp. Sig. (2-tailed) }\end{array}$ & $\begin{array}{l}\text { Mean } \\
\text { Std. Deviation } \\
\text { Absolute } \\
\text { Positive } \\
\text { Negative }\end{array}$ & $\begin{array}{l}.0000000 \\
2.61919065 \\
.062 \\
.062 \\
-.048 \\
.062 \\
.200^{\mathrm{c}, \mathrm{d}}\end{array}$ \\
\hline
\end{tabular}
a. Test distribution is Normal.
b. Calculated from data.
c. Lilliefors Significance Correction.
d. This is a lower bound of the true significance.

Berdasarkan hasil uji normalitas diketahui nilai signifikan 0,200>0,05, maka dapat disimpulkan bahwa nilai residual berdistribusi normal.

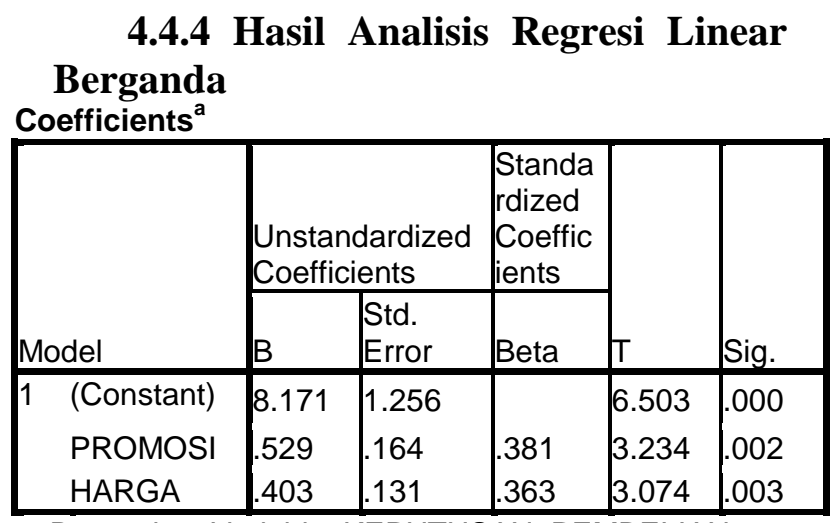

a. Dependent Variable: KEPUTUSAN_PEMBELIAN

Sumber : Data yang diolah dengan spss versi 23

Berdasarkan tabel 17, maka diperoleh persamaan regresi sebagai berikut :

$$
\mathrm{Y}=\mathbf{8 , 1 7 1}+\mathbf{0 , 5 2 9}+\mathbf{0 , 4 0 3}+\mathrm{e}
$$

Persamaan regresi tersebut dapat dijelaskan sebagai berikut

a. Konstanta sebesar 8,171; artinya jika Promosi $\left(\mathrm{X}_{1}\right)$ dan Harga $\left(\mathrm{X}_{2}\right)$ nilainya adalah 0, maka Keputusan Pembelian (Y) nilainya adalah $8,171 \%$.

b. Koefisien regresi variabel Promosi $\left(\mathrm{X}_{1}\right)$ sebesar 0,529; artinya jika variabel independent nilainya tetap dan
Keputusan Pembelian mengalami kenaikan sebesar 1\%, maka Keputusan Pembelian (Y) akan mengalami peningkatan sebesar $0,529 \%$. Koefisien bernilai positif artinya Promosi berpengaruh positif terhadap Keputusan Pembelian (Y), semakin meningkat Promosi maka semakin meningkat Keputusan Pembelian

c. Koefisien regresi variabel Harga $\left(\mathrm{X}_{2}\right)$ sebesar 0,403; artinya jika variabel independent nilainya tetap dan Harga mengalami kenaikan sebesar $1 \%$, maka Keputusan Pembelian (Y) akan mengalami peningkatan sebesar 0,403\%. Koefisien bernilai positif artinya Harga berpengaruh positif terhadap Keputusan Pembelian (Y), semakin meningkat Harga maka semakin meningkat Keputusan Pembelian.

\subsubsection{Hasil Uji Hipotesis Uji t}

\begin{tabular}{|c|c|c|c|c|c|}
\hline \multicolumn{6}{|l|}{ Coefficients $^{\mathrm{a}}$} \\
\hline \multirow[b]{2}{*}{ Model } & \multicolumn{2}{|c|}{$\begin{array}{l}\text { Unstandardized } \\
\text { Coefficients }\end{array}$} & \multirow{2}{*}{\begin{tabular}{|l} 
Standa \\
rdized \\
Coeffici \\
ents \\
Beta
\end{tabular}} & \multirow[b]{2}{*}{$\mathrm{T}$} & \multirow[b]{2}{*}{ Sig. } \\
\hline & $\mathrm{B}$ & \begin{tabular}{|l} 
Std. \\
Error
\end{tabular} & & & \\
\hline $1 \quad$ (Constant) & 8.171 & 1.256 & & 6.503 & .000 \\
\hline PROMOSI & .529 & .164 & .381 & 3.234 & .002 \\
\hline HARGA & .403 & .131 & .363 & 3.074 & .003 \\
\hline
\end{tabular}

a. Dependent Variable: KEPUTUSAN_PEMBELIAN

Sumber : Data yang diolah dengan spss versi 23, 2019

1) Promosi terhadap Keputusan Pembelian 
Berdasarkan hasil uji t diatas, diketahui nilai $t_{\text {hitung }}$ sebesar 3,234 dimana hasil

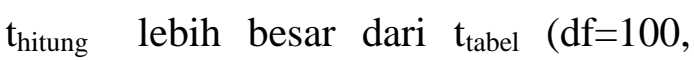
$\alpha=0,05)$ sebesar 1,660 atau 3,234> 1,660. Selain itu, diketahui nilai Sig dari Promosi adalah 0,002 atau kurang dari 0,05 atau $0,002<0,05$ maka Ho ditolak dan Ha diterima, yang artinya Promosi berpengaruh secara signifikan terhadap Keputusan Pembelian.

2) Harga terhadap Keputusan Pembelian Berdasarkan hasil uji t diatas, diketahu nilai $t_{\text {hitung }}$ sebesar 3,074 dimana hasil $t_{\text {hitung }}$ kurang dari $t_{\text {tabel }}(\mathrm{df}=100, \alpha=0,05)$ sebesar 1,660 atau 3,074 > 1,660. Selain itu, diketahui nilai Sig dari Harga adalah 0,003 atau kurang dari 0,05 atau 0,003 $<0,05$, maka Ho ditolak dan Ha diterima, yang artinya Harga berpengaruh secara signifikan terhadap Keputusan Pembelian.

\subsubsection{Hasil Uji F}

ANOVA $^{\mathrm{a}}$

\begin{tabular}{|ll|l|l|l|l|l|}
\hline Model & & Sum of Squares & Df & Mean Square & F & Sig. \\
\hline 1 & Regression & 667.884 & 2 & 333.942 & 47.695 & $.000^{\mathrm{D}}$ \\
& Residual & 679.156 & 97 & 7.002 & & \\
& Total & 1347.040 & 99 & & & \\
\hline
\end{tabular}

a. Dependent Variable: KEPUTUSAN_PEMBELIAN

b. Predictors: (Constant), HARGA, PROMOSI

Sumber : Data yang diolah dengan spss versi 23

Berdasarkan hasil uji $\mathrm{F}$, diketahui nilai signifikan untuk pengaruh $\mathrm{X}$ dan $\mathrm{X}_{2}$ secara simultan terhadap $\mathrm{Y}$ adalah sebesar
$0,0000<0,05$ dan nilai $F_{\text {hitung }} 47,695>$ $F_{\text {tabel }}$ 3,09, sehingga dapat disimpulkan bahwa $X_{1}$ dan $X_{2}$ berarti terdapat pengaruh

$$
\left(\mathbf{R}^{2}\right)
$$

\subsubsection{Analisis Koefisien Determinasi}

Tabel 19. Hasil Uji Koefisien

Determinasi

Model Summary ${ }^{\mathrm{D}}$

\begin{tabular}{|l|l|l|l|l|}
\hline Model & R & R Square & $\begin{array}{l}\text { Adjusted R } \\
\text { Square }\end{array}$ & $\begin{array}{l}\text { Std. Error } \\
\text { of the } \\
\text { Estimate }\end{array}$ \\
\hline 1 & $.752^{\mathrm{a}}$ & .566 & .536 & 1.73875 \\
\hline
\end{tabular}

a. Predictors: (Constant), HARGA, PROMOSI

b. Dependent Variable: KEPUTUSAN_PEMBELIAN

Sumber: Data yang diolah dengan spss versi 23

Berdasarkan tabel diatas diperoleh angka koefisien determinasi (adjusted R2) sebesar 0,566 atau 56,6 \%. Hal tersebut menunjukan bahwa Keputusan Pembelian dipengaruhi oleh Promosi (X1) dan Harga (X2) sebesar 0,566 atau 56,6\%, sedangkan sisanya sebesar $43,4 \%$ dijelaskan oleh variabel lain yang tidak termasuk dalam penelitian ini yakni diantaranya produk, tempat, orang, proses, periklanan, bukti secara simultan terhadap Y.

fisik.

\section{Hasil Pembahasan}

Permasalahan yang ingin dijawab dalam penelitian ini yaitu untuk mengetahui apakah Promosi dan Harga 
dapat berpengaruh terhadap Keputusan Pembelian pada PT. Shopee International Indonesia di kota Manado. Berdasarkan hasil analisis mengenai apakah Promosi dan Harga dapat berpengaruh terhadap Keputusan Pembelian pada PT. Shopee International Indonesia di kota Manado. dengan menggunakan SPSS versi 23, uji validitas semua variabel dikatakan valid. Sehingga dapat diambil kesimpulan bahwa semua pernyataan dalam kuesioner dapat digunakan dalam penelitian ini.

Pada bagian karateristik data responden dapat dilihat bahwa responden yang belum menikah, responden pelajar/mahasiswa, responden yang sudah lebih dari 1 tahun penggunaan, dan responden yang lebih dari 2 kali pembelian, merupakan responden yang jumlahnya paling banyak atau dominan. Dari penelitian ini juga telah menghasilkan data yang sudah diolah dengan SPSS menggunakan prinsip mengkorelasikan dan menghubungkan antara masing-masing skor item dengan skor total yang diperoleh dalam penelitian ini.

Dari data diatas, diketahui bahwa besar pengaruh promosi yaitu cukup mempengaruhi keputusan pembelian yang didukung dengan adanya periklanan yang mampu mempengaruhi konsumen, sehingga dari data responden diketahui tingkat tertinggi dari pernyataan responden yang menyatakan setuju ada pada indikator periklanan. Sedangkan dari data responden diketahui bahwa besarnya pengaruh harga yaitu yaitu cukup mempengaruhi keputusan pembelian.

Dari hasil penelitian yang sudah dilakukan peneliti, terdapat hubungan secara signifikan antara Promosi dan Harga terhadap Keputusan Pembelian. Berdasarkan tabel diatas diperoleh angka koefisien determinasi (adjusted R2) dimana hasil ini termasuk dalam kategori cukup atau sedang. Hal tersebut menunjukan bahwa Keputusan Pembelian cukup dipengaruhi oleh Promosi (X1) dan Harga (X2).

Sehingga dari hasi penelitian, mendukung teori Kotler dan Amstrong bahwa promosi dan harga berpengaruh untuk mempengaruhi keputusan pembelian yang didukung dengan adanya indicatorindikator seperti periklanan, penjualan pribadi, promosi penjualan, publisitas, keterjangkauan harga, harga yang sesuai dengan produk, harga sesuai dengan manfaat, harga yang mampu bersaing dengan perusahaan lain sehingga mempengaruhi keputusan pembelian yang sesuai dengan indikator-indikator pilihan produk, merek, dsb. dan berarti tujuan untuk mengetahui adanya pengaruh prmosi dan harga terhadap keputusan pembelian pada PT.Shopee International Indonesia di 
kota Manado sudah terbukti berdasarkan penelitian yang telah dilakukan.

\section{Simpulan}

Berdasarkan hasil penelitian ini dan pembahasan pada bab sebelumnya maka dapat disimpulkan bahwa Promosi dan Harga berpengaruh signifikan terhadap Keputusan Pembelian, hal ini menunjukan bahwa tingkat promosi dan harga yang dilakukan oleh pihak PT. Shopee International Indonesia sangat mempengaruhi keputusan pembelian konsumen.

Untuk itu penulis menyarankan beberapa hal yang mungkin dapat digunakan sebagai bahan pertimbangan karena Promosi dan Harga adalah unsur terpenting dan berpengaruh dalam Keputusan Pembelian, ada baiknya agar promosi yang dipromosikan agar disesuaikan dengan kenyataan yang sesuai dengan apa yang dipromosikan, juga untuk harga ada baiknya harga disesuaikan dengan barang yang dijual.

\section{Daftar Pustaka}

Budiyanto, Teguh. (2016). Strategi Promosi, Kualitas Produk dan Desain Terhadap Keputusan Pembelian dan Minat Merefrensikan Rumah pada Puri Camar Liwas PT. Camar Sapta Ganda. Jurnal Berkala Ilmiah Efisiensi, 16 (4).
Gerung, Christy. (2017). Pengaruh Kualitas Produk, Harga Dan Promosi Terhadap Keputusan Pembelian Mobil Nissan X-Trail Pada PT. Wahana Wirawan Manado. Jurnal Riset Ekonomi Manajemen Bisnis Akuntansi, 5 (2).

Kotler dan Keller. (2009). Manajemen Pemasaran. Jilid 1. Edisi ke 1. Jakarta: Erlangga.

Kotler, Philip. 2009. Prinsip-prinsip Manajemen Pemasaran. Jakarta: Salemba Empat.

Kotler, Philip \& Amstrong, (2012): Marketing Management 14th Edition. New Jersey: Pretice Hall.

Kotler, Philip \& Gerry Armstrong, (2014): Principle Of Markeing, 15th edition new. New Jersey: Pearson Pretice Hall.

Kotler, Philip \& Gerry Armstrong, (2016): Prinsi-prinsip Pemasaran. Edisi 13. Jilid 1. Jakarta: Erlangga

Sugiyono. 2015. Metode Penelitian Pendidikan (Pendekatan Kuantitatif, Kualitatif dan $R \& D)$. Penerbit $C V$. Alfabeta: Bandung.

Siregar, Syofian. (2013). Metode Penelitian Kuantitatif. Jakarta: PT. Fajar Interpratama Mandiri.

Wariki, Grace.(2015). Pengaruh Bauran Promosi, Persepsi Harga Dan Lokasi Terhadap Keputusan Pembelian Dan Kepuasan Konsumen Pada Perumahan Tamansari Metropolitan Manado. Jurnal Riset Ekonomi Manajemen Bisnis Akuntansi, 5 (2). 